\title{
DNA PROFILE OF COMMERCIAL PINEAPPLES IN MALAYSIA BY USING SSR MARKERS
}

\author{
SITI NORHAYATI ISMAIL ${ }^{*}$, NURUL SHAMIMI ABDUL GHANI ${ }^{2}$, SHAHRIL AB. RAZAK ${ }^{1}$, \\ RABIATUL ADAWIAH ZAINAL ABIDIN ${ }^{1}$, MOHD NIZAM ZUBIR ${ }^{2}$ and ROZLAILY ZAINOL ${ }^{3}$ \\ ${ }^{1}$ Biotechnology and Nanotechnology Research Centre, \\ Malaysian Agricultural Research and Development Institute (MARDI), \\ MARDI headquarters, Persiaran MARDI-UPM, 43400 Serdang, Selangor, Malaysia \\ ${ }^{2}$ Horticulture Research Centre, Malaysian Agricultural Research and Development Institute (MARDI), \\ MARDI Pontian, KM 53, Jalan Johor, 82000 Pontian, Johor, Malaysia \\ ${ }^{3}$ Industrial Crop Research Centre, Malaysian Agricultural Research and Development Institute (MARDI), \\ MARDI headquarters, Persiaran MARDI-UPM, 43400 Serdang, Selangor, Malaysia \\ *E-mail:yati@mardi.gov.my
}

Accepted 3 July 2021, Published online 31 December 2021

\begin{abstract}
Nine commercial varieties of pineapples in Malaysia (Josapine, Maspine, MD2, Sarawak, Gandul, N36, Moris, Crystal Honey and Yankee) were collected from various places in Peninsular Malaysia and analysed for cultivar identifications using nine simple sequence repeat (SSR) markers. A total of 27 alleles have been observed which ranged from 2 to 5 with an average of 3 alleles per locus. The polymorphic information content (PIC) value ranged from 0.3426 (Acom_82.8) to 0.6561 (Acom_67.2) with a mean of 0.4524 while the heterozygosity value ranged from 0.1097 (TsuAC021) to 0.8010 (TsuAC039) with a mean of 0.5481 . The pairwise Nei's genetic distances had also been calculated and the value ranged from 0.0562 (Gandul and Josapine) to 0.6383 (MD2 and Yankee) with an average value of 0.3169. The above data emphasised a moderate level of polymorphisms among the nine varieties. A dendrogram was constructed by using the unweighted pair group method with arithmetic mean (UPGMA) which showed all the nine successfully differentiated pineapple commercial varieties. A principal coordinate analysis (PCoA) was also had been generated which revealed an agreement with the dendrogram output. Therefore, these nine SSR markers can be used to identify the nine selected commercial varieties to ensure pure planting materials.
\end{abstract}

Key words: Commercial pineapple varieties, genetic identification, heterozygosity, simple sequence repeat (SSR)

\section{INTRODUCTION}

Pineapple (Ananas comosus (L.) Merr.) is the third most important tropical fruit produced in the world after banana and citrus (Md. Farid et al., 2015). It is mainly grown for its fruit, which is consumed fresh, processed or in the form of juice. Several by-products can also be extracted, especially fibre from the leave and the bromelain; a proteolytic enzyme contained in the fruit which is sometimes used in the food, cosmetic industries and also used as therapeutic treatment (Zatul et al., 2014; Rajendra et al., 2012). The entire plant is sometimes used as forage or a source of energy. In Malaysia, pineapple is a popular non-seasonal fruit and widely cultivated in Johor,

* To whom correspondence should be addressed. mainly at Kluang, Pontian, Muar, Kota Tinggi and Batu Pahat. Besides Johor, pineapple is also cultivated in Pahang, Kelantan, Perak, Sabah and Sarawak (MPIB, 2018). The pineapple industry in Malaysia is unique because $90 \%$ of pineapple is planted on peat soil and the remainder is planted on mineral soil.

Malaysia had been ranked as number five top pineapple exporter worldwide in the year 2017 and ranked nineteenth as the global pineapple producing country in the year 2013 which estimated to had produced a total of 315.997 metric tons to the global pineapple production (Agrofood Statistics, 2013; FAO, 2013; Suhana et al., 2019). However, Malaysia had fallen to rank $21^{\text {st }}$ for the global producer country in the year 2017 with an estimated production of 340,722 metric tons (MPIB, 2018). Besides fresh 
consumption, pineapples are also used in cooking (e.g. tart cookies and side dishes) and canned industry. Malaysia is famous for its canned golden yellow pineapple production. $95 \%$ of canned pineapple production is for export and the remaining $5 \%$ is for the domestic market. On the other hand, fresh pineapple contributes $30 \%$ to the export market and the rest is for the domestic market. Singapore is the traditional export market for fresh pineapples followed by Saudi Arabia, the United Arab Emirates, Brunei and Hong Kong (MPIB, 2021, web reference). An increase in demand for both canned and fresh pineapple contributes to many challenges for plant breeders to increase the production of the fruit. There are several pineapple cultivars (Josapine, Maspine, MD2, Sarawak, Gandul, N36, Morris, Crystal Honey and Yankee) available in Malaysia and each of them has its market values.

Cultivar identification is one of the major challenged aspects especially for vegetatively propagated crops like pineapple. The exchange of vegetative planting materials (crown, sucker and in vitro culture) among countries leads to genetic redundancy due to different naming conventions which causes common synonyms and homonyms among names of pineapple cultivar (Zhou et al., 2015). Cultivar identification is also important for cultivar right protection, which manifested under the Plant New Variety Protection (PNVP) act in 2004 that protects breeder's rights for their new plant varieties. PNVP act plays important role in recognizing farmer's hard work and effort, in developing, improving and conserving plant genetic resources (PGR) using various types of a method such as; cycles of selections, hybridizations and trading materials among other farmers, locally and globally. PGR is considered the most essential biological resource to ensure future food security, thus it has to be managed and conserved systematically and efficiently (Musa, 2017). Breeders usually have a number of accessions in their collection and each one of them need to be identified, characterized and managed systematically so there would be no duplication and mix among the accessions (Korir et al., 2013). In addition, environmental and climatic factors that could affect the plant phenotype also confer difficulty for the identification.

Therefore, the technology of molecular markers is used to assist the traditional method, which relies mainly only on morphological characters, for more precise and accurate identifications. A molecular marker is more stable compared to morphological data as it is obtained from the genome which is the blueprint of living things. The fact that DNA can be extracted at an early stage from any part of the plant makes molecular markers widely exploited for various purposes (Chambers et al., 2012; Shoda et al., 2012; Nybom et al., 2014). Several molecular identification studies of pineapple have been reported locally and internationally using internal transcribed spacer region (ITSR) (Hidayat et al., 2012), chloroplast marker (Hamdan et al., 2013), single nucleotide polymorphism (SNP) (Zhou et al., 2015) and simple sequence repeat (SSR) (Shoda et al., 2012). Simple sequence repeat (SSR) markers are one of the most preferable markers in genetic diversity studies due to their co-dominant inheritance, multi-allelic, high abundance and randomly distributed throughout the genome and also amenable to high throughput automation technologies, thus making it highly polymorphic and have highly reproducibly rate (Wen et al., 2010; Du et al., 2012; Sajib et al., 2012; Garkava-Gustavsson et al., 2013; Feng et al., 2014).

\section{MATERIALS AND METHODS}

\section{Plant materials}

Leaves of 30 individuals' plants for nine pineapple varieties (Josapine, Maspine, MD2, Sarawak, Gandul, N36, Morris, Crystal Honey and Yankee) were collected from multiple places in Peninsular Malaysia (Johor, Negeri Sembilan, Kedah, Pulau Pinang and Perak) including the fields maintained by the Horticulture Research Centre, MARDI Pontian, Johor; grown on peat soil, under standard cultural practices (without hormone for flower induction). The other fields were recommended by the Malaysian Pineapple Industrial Board (MPIB). Some were grown on peat soil and some on mineral soil, and the hormone ( $2 \%$ urea and $50 \mathrm{~mL}$ ethrel in 18 litres of water) was used for flower inductions.

\section{Molecular markers}

A total of 32 potential SSR markers, which have relatively high heterozygosity and a high number of alleles were selected for the screening (Kinsuat \& Kumar, 2007; Wöhrmann \& Weising, 2011; Shoda et al., 2012). Eventually, after PCR optimization and fragment analysis, only 9 polymorphic markers were selected for data analysis. The other markers were excluded due to non-specific binding (8 SSRs), monomorphic (6 SSRs) and poor amplification during PCR optimization in 2\% pre-stained agarose gel electrophoresis (5 SSRs) and also during fragment analysis using DNA Analyser (ABI3730XL, Applied Biosystems, USA) (4 SSRs). Detailed information for these nine markers is shown in Table 1.

\section{DNA extraction}

Total genomic DNA was extracted using a modified high-throughput plant DNA extraction method (Xin \& Chen, 2012). About $0.5 \mathrm{mg}$ of fresh pineapple leaf was added accordingly into the 96 well block plate (Corning Incorporated, USA) where 3 
tungsten beads $(3 \mathrm{~mm})$ were prior added into each of the wells. After being incubated inside the freezer $\left(-80^{\circ} \mathrm{C}\right)$ overnight, the plate was quickly placed onto the Tissue Lyser (Qiagen, Netherlands), and the frozen leaves were ground with frequencies of $30 \mathrm{~Hz}$ for one minute. Immediately, using a multichannel pipette, $600 \mu \mathrm{L}$ of DNA extraction buffer $(100 \mathrm{mM}$ Tris (pH 8.0), $200 \mathrm{mM}$ EDTA, $2 \%$ CTAB, $1.2 \mathrm{M} \mathrm{NaCl}$ and $0.1 \% \beta$-mercaptoethanol) was added into the plate wells, mixed well and incubated in $60^{\circ} \mathrm{C}$ water bath (Memmert, German) for 1 hour. After cooling down ( $\sim 5 \mathrm{~min}), 350 \mu \mathrm{L}$ chloroform: isoamyl alcohol (24:1) was added, mixed and centrifuged (Beckman Coulter, USA) at 5500 r.p.m. for $15 \mathrm{~min}$. Cold isopropanol (equal volume) was used for DNA precipitation followed by $70 \%$ ethanol washing $(200 \mu \mathrm{L})$. DNA pellet was air-dried and resuspended in $50 \mu \mathrm{L} \mathrm{TE}$ (Tris-EDTA) buffer.

\section{DNA quality assessment and normalization}

The quality of the extracted DNA was observed in $0.8 \%$ pre-stained (ethidium bromide) gel agarose electrophoresis. The image was visualized under ultraviolet light, Quantum ST4 3000 (Thermo Scientific, USA). DNA concentration was then measured using Thermo Labsystems Fluoroskan Ascent $^{\mathrm{TM}}$ (Thermo Scientific, USA) followed by DNA normalization at $30 \mathrm{ng} / \mu \mathrm{L}$ using the automated workstation, Janus (Perkin Elmer, USA).

\section{PCR amplification and fragment analysis}

The polymerase chain reaction (PCR) cocktail (10× PCR buffer (Invitrogen ${ }^{\mathrm{TM}}$, USA), $50 \mathrm{mM} \mathrm{MgCl}_{2}$ (Invitrogen ${ }^{\mathrm{TM}}$, USA), $2 \mathrm{mM}$ dNTPs (Invitrogen ${ }^{\mathrm{TM}}$, USA), $10 \mu \mathrm{M}$ of forward primer anchored with M13 tail (TGT AAA ACG ACG GCC AGT) (Schuelke, 2000), $10 \mu \mathrm{M}$ of unlabelled reverse primer and $5 \mu \mathrm{M}$ of M13 tail (fluorescently dyed with FAM, VIC, PET or NED), 5U Taq Polymerase (Invitrogen ${ }^{\mathrm{TM}}$, USA)) and approximately $30 \mathrm{ng} / \mu \mathrm{l}$ of template DNA with a total final volume of $10 \mu \mathrm{l}$ were used to perform polymerase chain reaction (PCR) using a thermal cycler (Applied Biosystems, USA). The PCR thermal condition was as follows: initial denaturation at $95^{\circ} \mathrm{C}$ for $5 \mathrm{~min}$, followed by 30 cycles at the annealing temperature of each primer pair (Table 1), $1 \mathrm{~min}$ extension at $72^{\circ} \mathrm{C}$ and the final extension at $72^{\circ} \mathrm{C}$ for $10 \mathrm{~min}$. Fragment analysis was conducted using DNA Analyser (ABI3730XL, Applied Biosystems, USA) with GeneScan ${ }^{\mathrm{TM}} 500$ LIZ (Applied Biosystems, USA) as a size standard, which can detect DNA fragments ranged from 35 to 500 base pair (bp).

\section{Data analysis}

DNA fragments produced by DNA analyser was scored using GeneMapper Software Version 4.0 (Applied Biosystems, USA). The genotypic data were then converted into several different formats by using
CONVERT software (Glaubitz, 2004). The presence of null alleles, scoring errors and large allele dropouts were analysed by using Micro-Checker, version 2.2 (Van Oosterhout et al., 2004). Power Marker software (version 3.5) was used to compute the number of alleles $\left(\mathrm{N}_{\mathrm{A}}\right)$ per locus, the heterozygosity value as well as the polymorphism information content (PIC) of each SSR marker (Liu \& Muse, 2005). UPGMA dendrogram was also formulated via Power Marker software (version 3.5) using calculated genetic distance Nei's and subsequently visualized using MEGA version 7.0.18 (Kumar et al., 2016). Lastly, the principal coordinate analysis ( $\mathrm{PCoA})$ was generated by using GenAlEx 6.5 using the Nei Pairwise genetic distance (Peakall \& Smouse, 2012).

\section{RESULTS AND DISCUSSIONS}

There were neither scoring errors, large allele dropouts nor null alleles had been found for all the nine SSR markers after being analysed via MicroChecker 2.2. The details for each marker are shown in Table 1. Overall, 27 alleles had been recognized through the screening of these nine SSR markers. The alleles ranged from 2 to 5 alleles with a mean of 3 alleles per locus. Three of the markers (TsuAC039, TsuAC021 and Acom 82.8) had identified 2 alleles while four markers (TsuAC008, TsuAC013, TsuAC030 and TsuAC041) had identified 3 alleles. On the other hand, SSR markers TsuAC010 and Acom_67.2 had identified 4 and 5 alleles respectively.

The polymorphic information content (PIC) number ranged from 0.3426 (Acom_82.8) to 0.6561 (Acom_67.2) with a mean of 0.4524 while the heterozygosity value ranged from 0.1097 (TsuAC021) to 0.8010 (TsuAC039) with a mean of 0.5481 . The higher value of PIC illustrates the higher strength of the marker to assess the variations in a population and it is highly relying on the number of alleles together with its distribution frequencies (Liu and Cordes, 2004). Meanwhile, the higher value of heterozygosity illustrates the higher variations in the particular locus. Thus, the mean value of PIC could signify the degree of genetic variations in a population, whereby in the case of this study, the population revealed a moderate level of variations where the average PIC value was between 0.2500 and 0.5000 (Sharma et al., 2016). A moderate level of polymorphism was expected in commercial varieties and also for vegetative planting materials. This is due to repetitive used of the same elite varieties for crop improvement and there was also no segregation expected from vegetative planting materials. On the other hand, a higher level of polymorphism was expected from germplasm collections and seed planting materials as more accessions from different 


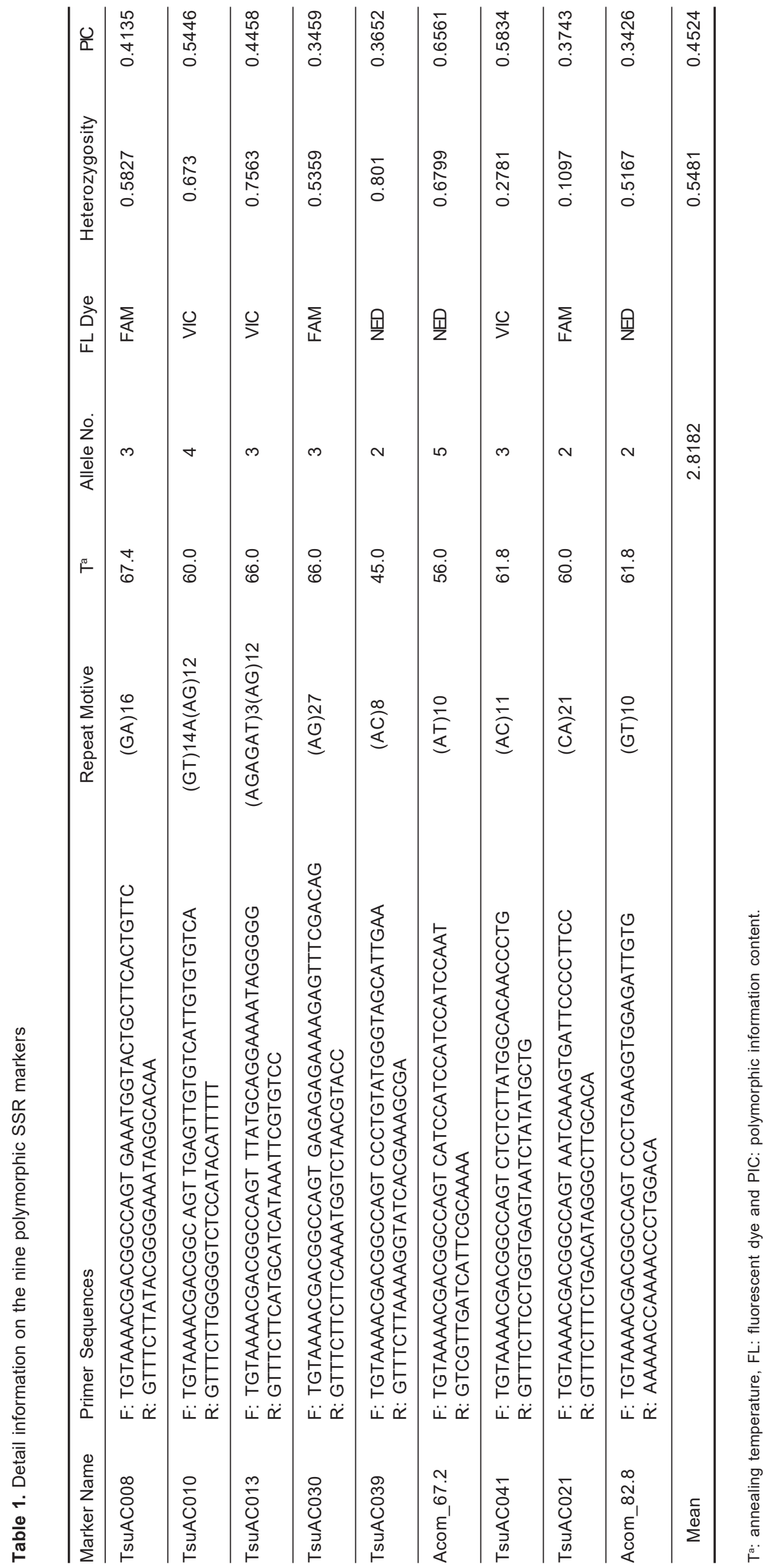


Table 2. Pairwise Nei's genetic distances showing genetic relationships between the nine pineapple varieties

\begin{tabular}{lccccccccc}
\hline OTU & CH & Gandul & Josapine & Maspine & MD2 & Moris & N36 & Sarawak & Yankee \\
\hline CH & 0.0000 & 0.2802 & 0.2586 & 0.3019 & 0.4310 & 0.2081 & 0.4019 & 0.2584 & 0.4045 \\
Gandul & 0.2802 & 0.0000 & 0.0562 & 0.4630 & 0.4812 & 0.0712 & 0.1814 & 0.4495 & 0.4422 \\
Josapine & 0.2586 & 0.0562 & 0.0000 & 0.4500 & 0.5292 & 0.0804 & 0.1902 & 0.4405 & 0.3898 \\
Maspine & 0.3019 & 0.4630 & 0.4500 & 0.0000 & 0.2212 & 0.3964 & 0.5500 & 0.3424 & 0.4589 \\
MD2 & 0.4310 & 0.4812 & 0.5292 & 0.2212 & 0.0000 & 0.4644 & 0.4457 & 0.3982 & 0.6383 \\
Moris & 0.2081 & 0.0712 & 0.0804 & 0.3964 & 0.4644 & 0.0000 & 0.1554 & 0.3761 & 0.4350 \\
N36 & 0.4019 & 0.1814 & 0.1902 & 0.5500 & 0.4457 & 0.1554 & 0.0000 & 0.3471 & 0.4549 \\
Sarawak & 0.2584 & 0.4495 & 0.4405 & 0.3424 & 0.3982 & 0.3761 & 0.3471 & 0.0000 & 0.3822 \\
Yankee & 0.4045 & 0.4422 & 0.3898 & 0.4589 & 0.6383 & 0.4350 & 0.4549 & 0.3822 & 0.0000 \\
\hline
\end{tabular}

origins were usually included in the germplasm collection and there were also segregations anticipated from seed planting materials.

In addition, the Pairwise genetic distances had also been calculated and the value ranged from 0.0562 (Gandul and Josapine) to 0.6383 (MD2 and Yankee) with an average value of 0.3169 (Table 2). The lower value of the genetic distance represented the higher relationship between each other. Thus, these data indicated a close relationship between Gandul and Josapine. It might be because both of them are from the Spanish group. Gandul was the main cultivar used for the canning industry in Malaysia for over a century before it was then replaced by MD2, Moris and N36 due to its sudden decrease in yield. Both Gandul and Josapine have red spiny colour in their leaves with attractive deep golden yellow flesh colour. On the other hand, less relationship can be observed involving MD2 and Yankee in comparison to the other varieties. MD2 comes from the Cayenne group and has a cylindrical fruit shape with very minimal spines at the tip of the leaf while Yankee comes from the Queen group and has a tapered fruit shape with complete spines all along the leaf. These highly distinguished characteristics might contribute to their distant genetic relationship.

A dendrogram was constructed by using the UPGMA showing all the nine successfully differentiated pineapple varieties. These pineapple varieties were group into two clusters based on the leaf types. There are 3 identified leaf margins of pineapple; 1) complete spine leaf type, 2) complete spineless also known as piping leaf type and, 3) also spiny-tip leaf type. The spiny-tip leaf signifies the spines that are only present at the tip of the leaf. This form usually occurs due to condition in the plant which initiates the leaf growth during the beginning of the leaf's growth; after a while, the production of spines stop therefore leaving spines only at the tips of the leaf (Collins \& Kerns, 1946). The first cluster which includes N36, Josapine, Gandul, Moris, Yankee, Crystal Honey and Sarawak can be identified as a spiny leaf group. Moris, Yankee and Crystal
Honey have complete spines all along the leaf; Josapine and N36 have marginal uneven spines also all along the leaf while Sarawak and Gandul have spiny-tip leaf type. The second cluster consists of Maspine and MD2 where both are from the Cayenne group. The similar morphological characteristics that they shared are having smooth and shiny leaves, cylindrical fruit shape, low citric acid (0.3-0.43\%) and high sugar content (15-17\% Brix) (unpublished data). Maspine is known to have a piping leaf type (complete spineless) which is a trait preferred by pineapple producers as well as consumers, as it is easier to handle and to manage (Naoya et al., 2015) although MD2 has very minimal spines at the tip of the leaf.

Moreover, principal coordinate analysis (PCoA) also had been generated using Nei's Pairwise genetic distance (Figure 1). The first three axes of differentiation explained $82.78 \%$ of the total variation (Table 3). Similar to the constructed UPGMA dendrogram (Figure 2), all 9 pineapple varieties were clearly separated from one another. The coordinates of Moris, Josapine and Gandul were closer to each other as they shared the highest relationship compared to the others. Besides, the genetic distances between Moris and Josapine (0.0924) and also between Josapine and Gandul (0.0726) were generally low indicating a close relationship among each other (Table 2). There were no other obvious clusters can be observed as the other six varieties were further separated from one another. However, the observation shows that MD2 and Maspine are the closest to each other compared to the others. The same goes for Crystal Honey and Sarawak which explains the clusters in the dendrogram (Figure 2).

Table 3. Percentage of variation explained by the first three axes using nine SSR markers in PCoA

\begin{tabular}{lccc}
\hline Axis & 1 & 2 & 3 \\
\hline$\%$ & 42.65 & 22.65 & 17.48 \\
Cum \% & 42.65 & 65.30 & 82.78 \\
\hline
\end{tabular}




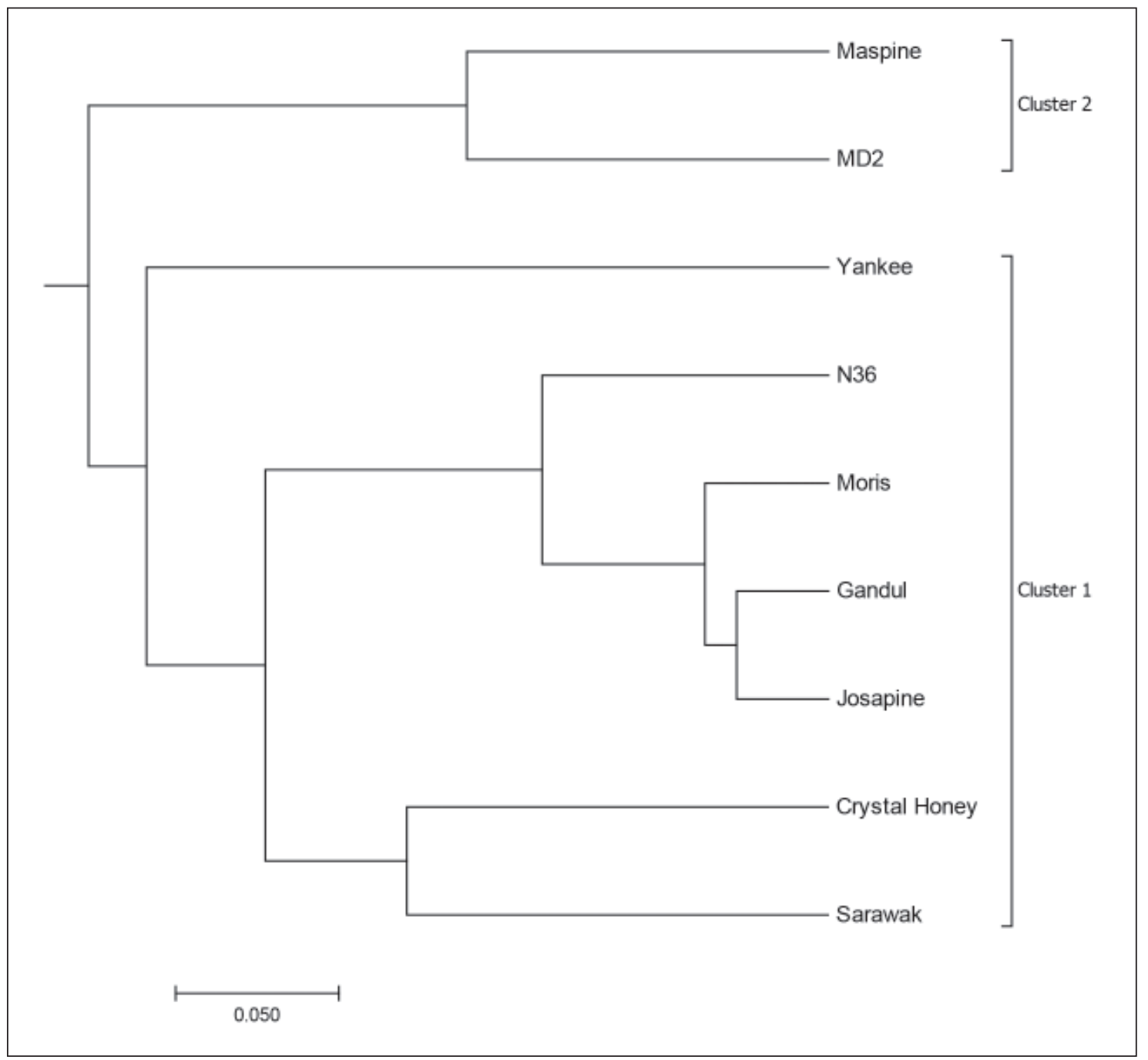

Fig. 1. UPGMA cluster dendrogram showing the relationships of nine pineapple varieties based on nine polymorphic SSR markers. Two major clusters can be observed (Cluster 1 and Cluster 2).

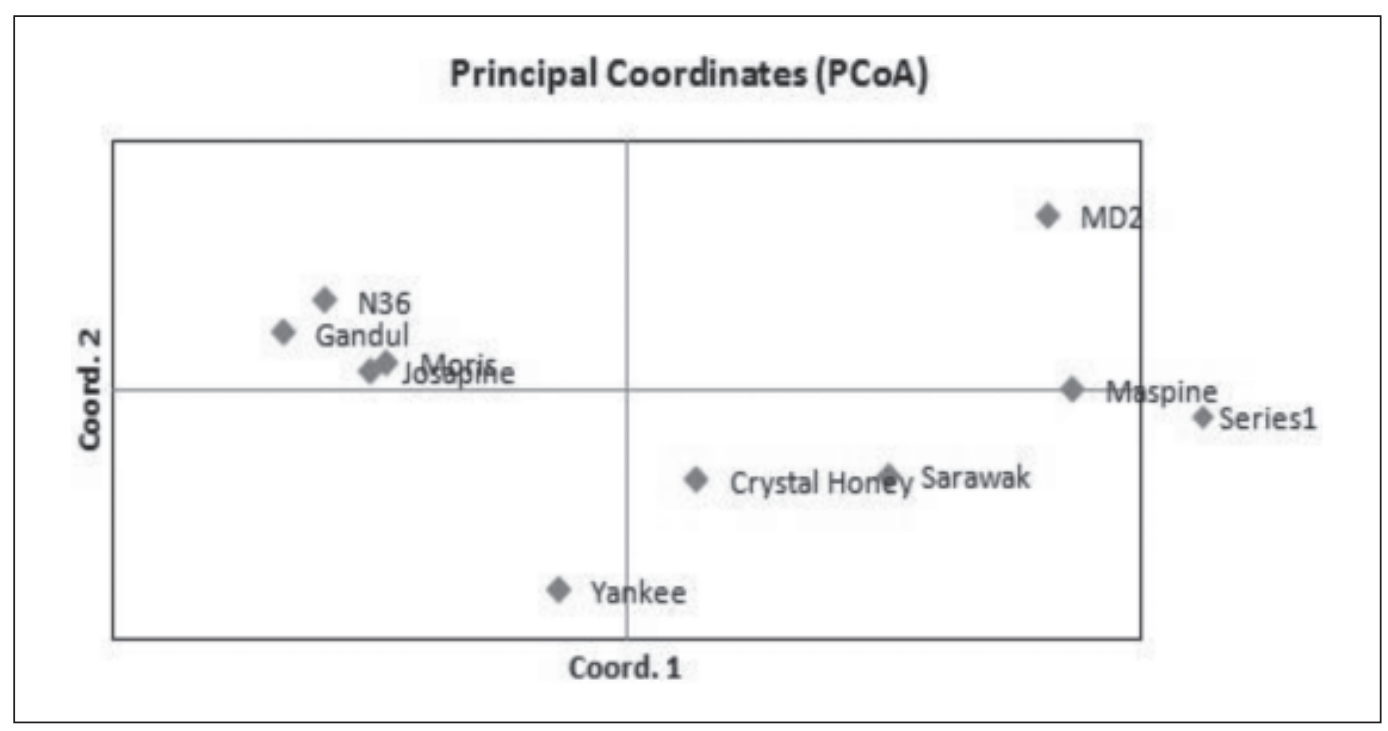

Fig. 2. Principle coordinates Analysis ( $\mathrm{PCoA}$ ) shows that all the nine varieties were successfully distinguished among each other by using nine SSR markers. Moris, Gandul and Josapine were clustered together showing close relationships between them. 


\section{CONCLUSIONS}

Evidently, all the nine pineapple commercial varieties (Josapine, Maspine, MD2, Sarawak, Gandul, N36, Morris, Crystal Honey and Yankee) can be differentiated between one another using these nine polymorphic SSR markers even though the data emphasised a moderate level of polymorphisms among the nine varieties. Nonetheless, the moderate level of polymorphism was expected in commercial varieties and also for vegetative planting materials. Thus these 9 SSR markers can be used to ensure pure planting materials of the above varieties.

\section{ACKNOWLEDGEMENT}

This project was funded by the National Key Economic Area (NKEA) Entry Point Project 14 (EPP 14) grant. We thank our project members from the Biotechnology and Nanotechnology Research Centre and also members from the Horticulture Research Centre who were directly or indirectly involved in this study. A special thanks to the Malaysian Pineapple Industry Board (MPIB) and the Department of Agriculture (DOA) for their cooperation in making this project successful.

\section{REFERENCES}

Chambers, A., Whitaker, V.M., Gibbs, B., Plotto, A. \& Folta, K.M. 2012. Detection of the linaloolproducing NES1 variant across diverse strawberry (Fragaria spp.) accessions. Plant Breeding, 131(3): 437-443.

Collins, J.L. \& Kerns, K.R. 1946. Inheritance of three leaf types in the pineapple. Journal of Heredity, 37(4): 123-128.

Du, Q., Wang, B., Wei, Z., Zhang, D. \& Li, B. 2012. Genetic diversity and population structure of Chinese white poplar (Populus tomentosa) revealed by SSR markers. Journal of Heredity, 103(8): 853-862.

Feng, X., Wang, Y. \& Gong, X., 2014. Genetic diversity, genetic structure and demographic history of Cycas simplicipinna (Cycadaceae) assessed by DNA sequences and SSR markers. Biomedcentral Plant Biolology, 14: 187.

Garkava-Gustavsson, L., Mujaju, C., Sehic, J., Zborowska, A., Backes, G.M., Hietaranta, T., Antonius, K. 2013. Genetic diversity in Swedish and Finnish heirloom apple cultivars revealed with SSR markers. Scientia Horticulture, 162: 43-48.

Glaubitz, J.C. 2004. CONVERT/ : A user-friendly program to reformat diploid genotypic data for commonly used population genetic software packages 309-310. Molecular Ecology Notes, 4(2): 309-310.

Hamdan, N., Abd Samad, A., Hidayat, T. \& Mohd Salleh, F. 2013. Phylogenetic analysis of eight Malaysian pineapple cultivars using a chloroplastic marker (rbcL. gene). Jurnal Teknologi (Sciences and Engineering), 64(2): 29-33.

Hidayat, T., Abdullah, F.I., Kuppusamy, C., Samad, A.A. \& Wagiran, A. 2012. Molecular identification of Malaysian pineapple cultivar based on internal transcribed spacer region. $A P C B E E$ Procedia, 4: 146-151.

Kinsuat, M.J. \& Kumar, S.V. 2007. Polymorphic microsatellite and cryptic simple repeat sequence markers in pineapples (Ananas comosus var. comosus). Molecular Ecology Notes, 7(6): 10321035.

Korir, N.K., Han, J., Shangguan, L., Wang, C., Kayesh, E., Zhang, Y. \& Fang, J. 2013. Plant variety and cultivar identification: Advances and prospects. Critical Reviews in Biotechnology, 33(2): 111-125.

Kumar, S., Stecher, G., Tamura, K. \& Medicine, E. 2016. MEGA7: Molecular Evolutionary Genetics Analysis version 7.0 for bigger datasets. Molecular Biololy and Evolution, 33(7): 18701874.

Liu, K. \& Muse, S.V. 2005. PowerMarker: An integrated analysis environment for genetic marker analysis. Bioinformatics Applications Notes, 21(9): 2128-2129.

Liu, Z.J. \& Cordes, J.F., 2004. DNA marker technologies and their applications in aquaculture genetics. Aquaculture, 238(1-4): 1-37.

Malaysian Pineapple Insdustry Board (MPIB). 2018. Maklumat Statistik Industri Nanas 2018. Lembaga Perindustrian Nanas Malaysia, Johor Bahru, Johor. pp. 1-5 (Malay).

Malaysian Pineapple Industry Board (MPIB). 2021. URL http://www.mpib.gov.my/pasaran (accessed on 01.07.2021)

Md. Farid, H., Shaheen, A. \& Mustafa, A. 2015. Nutritional value and medicinal benefits of pineapple. International Journal of Nutrition and Food Sciences, 4(1): 84-88.

Musa, M.K. 2017. Protection of Malaysia small farmers under the plant variety law: An Appraisal. Atlantic Press, 84: 124-129.

Naoya, U., Satoko, G., Risa, K., Tomonori, T., Kazuhiko, T., Makoto, T., Chie, M., Kaname, Y., Fumiko, H., Shingo, T., Hideo, M., Toshiya, Y. \& Moriyuki, S. 2015. Leaf margin phenotypespecific restriction-site-associated DNA-derived markers for pineapple. Breeding Science, 65(3): 276-284. 
Nybom, H., Weising, K. \& Rotter, B. 2014. DNA fingerprinting in botany: Past, present, future. Investigative Genetics, 5: 1-35.

Peakall, R. \& Smouse, P.E. 2012. GenAlEx 6.5: Genetic analysis in Excel. Population genetic software for teaching and research - an update. Bioinformatics Applications Notes, 28(19): $2537-$ 2539.

Rajendra, P., Sapna, J., Shraddha \& Ajay, K. 2012. Properties and therapeutic application of bromelain: A review. Hindawi Publishing Corporation Biotechnology Research International, 2012: 976203.

Sajib, A.M., Hossain, M. \& Ali, S. 2012. SSR markerbased molecular characterization and genetic diversity analysis of aromatic landreces of rice (Oryza sativa L.). Journal of Bioscience Biotechnology, 1(2): 107-116.

Sharma, R., Kumar, B., Arora, R., Ahlawat, S., Mishra, A.K. \& Tantia, M.S. 2016. Genetic diversity estimates point to immediate efforts for conserving the endangered Tibetan sheep of India. Meta Gene, 8: 14-20.

Shoda, M., Urasaki, N., Sakiyama, S., Terakami, S., Hosaka, F., Shigeta, N., Nishitani, C. \& Yamamoto, T. 2012. DNA profiling of pineapple cultivars in Japan discriminated by SSR markers. Breeding Science, 62(4): 352-359.

Suhana, S., Joanna, C.L.Y., Wan M.R.I.W.H, Mohd, Z.M.A., Nur, A.R. \& Razali, M. 2019. Japan as a new market for Malaysian pineapples [WWW Document]. Food and Fertilizer Technology Centre for the Asian and Pacific Region (FFTC) Newsletter. URL http://ap.fftc.agnet.org/ ap_db.php?id=1099\&print $=1$ (accessed on 06.15.20).
Van Oosterhout, C., Hutchinson, W.F., Wills, D.P.M. \& Shipley, P. 2004. MICRO-CHECKER: Software for identifying and correcting genotyping errors in microsatellite data. Molecular Ecology Notes, 4(3): 535-538.

Wen, M., Wang, H., Xia, Z., Zou, M., Lu, C. \& Wang, W. 2010. Development of EST-SSR and genomicSSR markers to assess genetic diversity in Jatropha Curcas L. Biomed Central Research Notes, 3: 42.

Wöhrmann, T. \& Weising, K. 2011. In silico mining for simple sequence repeat loci in a pineapple expressed sequence tag database and crossspecies amplification of EST-SSR markers across Bromeliaceae. Theoretical and Applied Genetics, 123: 635-647.

Xin, Z. \& Chen, J. 2012. A high throughput DNA extraction method with high yield and quality. Plant Methods, 8: 26.

Zatul, I.M.A, Azura, A., Faridah, Y., Irwandi, J., Kausar, A. \& Show, P.L. 2014. Bromelain: An overview of industrial application and purification and purification strategies. Applied Microbiology and Biotechnology, 98: 72837297.

Zhou, L., Matsumoto, T., Tan, H.-W., Meinhardt, L.W., Mischke, S., Wang, B. \& Zhang, D. 2015. Developing single nucleotide polymorphism markers for the identification of pineapple (Ananas comosus) germplasm. Hortiulture Research, 2: 15056. 